\title{
Long-Term evaluation of biogas energy potential based on the neuronal network approach
}

\author{
Córdova-Suárez, $M^{1,{ }^{*}}$, Sosa-Cárdenas, $J .{ }^{1}$, Cifuentes-Suárez, $Y .{ }^{1}$, Sánchez-Almeida, $L .{ }^{2}$ \\ ${ }^{1}$ Technical University of Ambato (UTA) School of Food Science and Engineering. Ambato (Ecuador) \\ ${ }^{2}$ Technological University Indoamérica, Ambato (Ecuador)
}

\begin{abstract}
The energy potential of biogas is estimated from the biomass quantity, that is, a biodegradability values obtained from the organic fraction of municipal solid waste (MSW). In this study, the percentage contribution of each and every type of waste was quantified according to the waste classification., In addition, the waste generation data was projected by applying both artificial neural network (ANN) and mathematical models and 4 types of biomass wastes which accounts for a contribution of about $63 \%$ of the total waste sampled were obtained. The projection of the weights of the waste was carried out from 2015 to 2030, with the application of the neural network model with Backpropagation. All in all, under the application of the mathematical models, it has been shown that the Ecuadorian model predicted not only a high average volume, but also a large annual value of biogas energy.
\end{abstract}

\section{Introduction}

Municipal solid waste (MSW), also known as trash, are generated from human activities. As such, the amounts of MSW are closely related to the growth and economy of the world population. In fact, the Urban Solid Waste (USW) is carried out in the landfills of each Municipal Autonomous Decentralized Government (ADG) in Ecuador, where some of the USW will be considered as biomass if they could produce methane (biogas) after their decomposition. From there, the energetic potential of biomass in the form of biogas will be estimated. Having said that, as there is no measurement of the accuracy of the generation of USW the advanced dynamic techniques are applied are in order to achieve accuracy and consistency in the USW generation. These methods mainly consist of fuzzy logic, time-series methods and artificial neural networks. It is important to note that, the number of neurons pattern corresponds to the number of data patterns, and the number of neurons in the sum sub-layer is consistently greater than one compared to the number of output neurons.

Neural models are frequently used to classify patterns and make predictions based on the algorithms of past learning experiences of Artificial Intelligence and Machine Learning. The most useful model among them is the Neuronal Network with Back-propagation (NNB), given its low percentage of absolute error, as compared to the Neuronal General Regression Network model NGRN which has a percentage of absolute error of $6.7 \%$ [1].

In the case of supervised training that is used for the multilayer networks, where the outputs of each layer are connected to all the neurons in the next layer, those connections are known as dendrites, as shown in Fig. 1, wherein an analogy with the human neurons are made. [2]

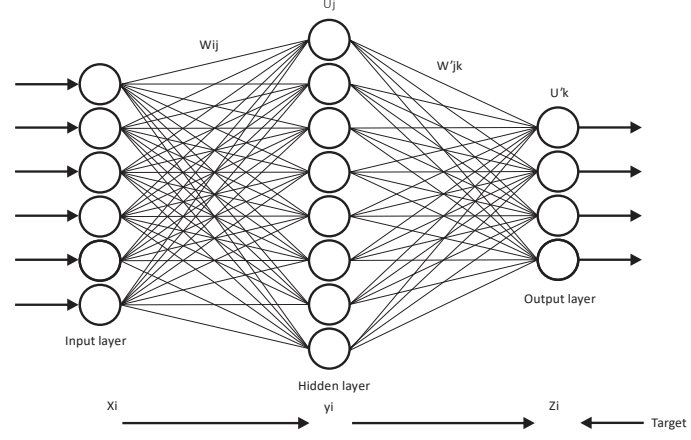

Fig. 1. Artificial neuronal network

Part of the USW generation projection of Salcedo, the capital city of the Hermanas Mirabal Province (Located in Ecuador) corresponds to the type of biomass waste, where methane is produced as a by-product of its decomposition. Biomass being the biodegradable fraction of products, waste and municipal waste generated in private homes, businesses, offices and industries are obtained from the degradation of biomass which is created by the anaerobic bacteria. [3]

Biogas is a gas composed principally of methane (CH4) in an average fraction between $40-70 \%$ and carbon dioxide (CO2). Biogas has been called renewable natural gas, since it provides an alternative fuel source to reduce the amount of methane emissions to the atmosphere. To estimate the energetic potential of the biogas, the Mexican and Ecuadorian models are used. These models are influenced by the methane valuation index, methane

* Corresponding author: ma.cordova@uta.edu.ec 
correction factor, fire impact adjustments and biomass types. (Quintana, 2016)

The purpose of this research is to apply a NNB multilayer, where the number of neurons in the input layer corresponds to the number of input variables, while the number of neurons in the output layer is equal to the number of output variables. It is important to mention that the present work has allowed an estimation of the energy generated with only the error of the mathematical models application, wherefor the projection of the urban solid waste USW weights was carried out from 2015 to 2030 under the application of the neuronal network model with back- propagation was able to make the data closer reflect what is seen in reality. Simply, the Ecuadorian model applied has presented a better figure for the average volume of production of annual biogas and consequently, an energy value per year.

\section{Materials and methods}

\subsection{Determination of the sample number}

The simple random sampling method was used, for which the following equation 1 [4] was applied:

$$
n=\frac{y^{2} * p * q * N}{E^{2} *(N-1)+y^{2} * p * q}
$$

Where: $\mathrm{n}=$ sample size; $\mathrm{N}=$ size of the population; $\mathrm{p}$ $=$ probability of occurrence; $\mathrm{q}=$ probability of nonoccurrence; $\mathrm{E}=$ sample error; $\mathrm{y}=$ confidence level.

The probability of occurrence was $87 \%$ while the probability of non-occurrence was $13 \%$ based on the weights of history. Likewise, the error in the sample selected was only $5 \%$ with a confidence level of $95 \%$.

\subsection{Classification of the type of generated waste}

Table 1. Classification USW from the city of Salcedo. [5].

\begin{tabular}{|c|c|}
\hline Material & Specification \\
\hline Paper & $\begin{array}{l}\text { Books, magazines, newspapers, office } \\
\text { paper, notebooks, scraps of paper, }\end{array}$ \\
\hline Cardboard & Boxes, containers, tetra pack \\
\hline Glass & Bottles, containers, crystals \\
\hline Metal & Cans, scrap \\
\hline Plastics & Bottle, covers, foam flex \\
\hline $\begin{array}{l}\text { Miscellaneous } \\
\text { fuels }\end{array}$ & $\begin{array}{c}\text { Sanitary waste (diapers, sanitary } \\
\text { napkins), textiles, rubber. }\end{array}$ \\
\hline Organic waste & Food waste \\
\hline Garden garbage & $\begin{array}{c}\text { Animal droppings, pruning residue and } \\
\text { flowers }\end{array}$ \\
\hline Inert & Ceramics, construction waste \\
\hline
\end{tabular}

Table 1 classifies types of common waste materials found in the garbage disposal sites. It can be seen both organic and inorganic material.

\subsection{Determination of the waste contribution that can be used for the generation of biogas}

The classified products were weighed separately on the weighing machine and the result was recorded. The contribution percentage of the USW was calculated using the following equation 2, based on the Mexican regulations of 1992 [6].

$$
P S=\frac{G_{1}}{G} * 100
$$

Where:

Ps = percentage of the considered product;

$\mathrm{G} 1$ = weight of the considered product, expressed in $\mathrm{kg}$;

$\mathrm{G}=$ total weight, sum of the sampled days $(720 \mathrm{~kg})$.

\subsection{Prediction of the annual generation of urban solid waste using a model of NNB}

The neurons developed from the programming and mathematical models act in a group and where all the input data were processed at the same time and then added with the non-linear activation functions. Equation (3) represents the response of the Artificial Neuronal Network of Fig. 1.

$$
y=f\left(\sum_{k} w_{n} x_{n}\right)
$$

Where: $x_{n}$ : Output signal from other input nodes; $w_{n}$ : Weights of each connection; $f(*)$ :Non-linear function, which can be sigmoidal, hyperbolic tangent, etc., in order to facilitate approximations of the Tan-Sigmoid activation function of equation (4).

$$
\operatorname{tansig}(x, y)=\frac{2}{1+e^{2(x+y)}}-1
$$

The Representation of Artificial Neuron (RAN) used a supervised learning paradigm in a Perceptron network, Rosenblatt (1958). This approach is then carried out by applying the Multilayer feature in which the hidden layers performed a more complex processing of input vector $\mathrm{x}(\mathrm{n})$, with the Tan-Sigmoid function as non-linear activation of the neuron. The algorithm used in a Multilayer Perceptron called Back-propagation is based on the delta rule to correct the instantaneous error, which is shown in equation 5 [7].

$$
e_{i n s t}(n)=\frac{1}{2} \sum_{j \in C} e j^{2}(n)
$$

Where: $e_{\text {inst }}$ : instantaneous error; $\mathrm{C}$ : neuron vector of the output layer; n: number of samples with which the RAN was trained.

Being able to express the average of the squared with equation 6 .

$$
e_{a v}=\frac{1}{N} \sum_{n=1}^{N} e_{\text {inst }}(n)
$$

Where:

$e_{a v}:$ average error;

$\mathrm{N}$ : number of samples.

For the accurate or precise predictions under the NNB, it is very important to identify the parameters that significantly affect the amount of waste generated with other. [8] In addition, the different indicators that are related to the economy, demography, industry and 
environmental phenomena, as well as the social and consumer habits, were used as the initial input variables. [9].

The training algorithm has the objective of minimizing the number of errors on all training sets. The training iterations which are called epochs will update the weights of both the input and output layers together with the weights of the hidden layers. The number of inputs of the designed neural network were 9 and described in Table 2.

Table 2. Inputs of the designed NNB

\begin{tabular}{|c|c|c|}
\hline INPUT N $^{\circ}$ & VARIABLE & UNITS \\
\hline 1 & $\begin{array}{c}\text { Gross Domestic Product } \\
\text { (GDP) }\end{array}$ & \$ million \\
\hline 2 & Urban population & Fraction \\
\hline 3 & Population Density & person $/ \mathrm{km}^{2}$ \\
\hline 4 & Average household size & $\begin{array}{c}\text { people per } \\
\text { household }\end{array}$ \\
\hline 5 & Industry, added value & Fraction \\
\hline 6 & $\begin{array}{c}\text { Tourism expenses in the } \\
\text { country }\end{array}$ & \$ per person \\
\hline 7 & $\begin{array}{c}\text { Population by age group } \\
\text { of 15-65 }\end{array}$ & Fraction \\
\hline 8 & $\begin{array}{c}\text { Household final } \\
\text { consumption expenditure }\end{array}$ & \$raction \\
\hline 9 & $\mathrm{CO}_{2}$ emissions & r \\
\hline
\end{tabular}

\subsection{Estimation of the biogas energetic potential}

The energy potential of biogas was calculated based on the application of the Mexican and Ecuadorian biogas models, which are the variations of the biogas model of the United States Environmental Protection Agency (USEPA). The Mexican biogas model was based on equation 7 [10].

$$
Q_{L F G}=\sum_{t=1}^{n} \sum_{j=0,1}^{1} 2 k L o\left[\frac{M i}{10}\right]\left(e^{-k t_{i j}}\right)(C F M)(F)
$$

Where:

QLFG = Biogas generation index expressed in $\mathrm{m} 3 /$ year; $\mathrm{i}=$ Increase in one-year time; $\mathrm{n}=$ (year of calculation) - (initial year of using USW); $\mathrm{j}=$ Increment of time in 0.1 years; $\mathrm{k}=$ Methane generation index expressed in 1/year; L0 = Maximum methane generation potential expressed in $\mathrm{m} 3 / \mathrm{ton}$; $\mathrm{Mi}=$ Mass of USW (considered biomass) arranged in the year in ton; tij = Age of USW deposited expressed in years; CFM = Correction factor for methane; $\mathrm{F}=$ Fire adjustment factor.

Equation 8 taken from the Urquizo and Siliezar (2009) was used to estimate the energy potential of biogas from the Ecuadorian model.

$$
Q=\sum_{0}^{n} \frac{1}{\% \text { vol }} k L o M e^{-k\left(t-t_{\text {lag }}\right)}
$$

Where: $\mathrm{Q}=$ Biogas generation index expressed in $\mathrm{m} 3$ /year; $\mathrm{n}=$ Number of analyzed years; $\mathrm{t}=$ Time in years since the garbage was deposited; tlag = Estimation of time from the placement of garbage and generation of methane; $\% \mathrm{vol}=$ estimation of volumetric percentage of methane in the biogas; $\mathrm{k}=$ methane generation index expressed in 1/year; Lo $=$ maximum methane generation potential expressed in $\mathrm{m} 3 /$ ton; $M=$ mass of USW (considered biomass) arranged in the year in tons.

The values of the indexes $\mathrm{k}(0.065)$ and Lo (84) are dependent on the precipitation index (mm/year) of the study area. The area of study (city of Salcedo) is located in the inter-Andean region of the Ecuador (Country in South America) and for this area the rainfall rate exceeds $500 \mathrm{~mm} /$ year [11].

The mass of the USW expressed in tons from 2015 to 2030 was projected with the model of NNB. The CFM value refers to an adjustment to the estimation of the biogas potential which is based on the type of anaerobic decomposition management of the biomass and the depth at which the biomass is placed in the final disposal. In this study, it was assumed that the value of $C F M=0.8$, which means that the depth of the place of final disposal of the biomass was greater than 5 meters and that the management conditions of the place with respect to the treatment of the biomass were unknown. The transformation of the volume of biogas produced annually (m3/year) to electrical energy ( $\mathrm{kW} / \mathrm{h})$ was carried out based on the methane combustion reaction 9 , taking into account that $50 \%$ of the biogas in the methane forms obtained that is shown in equation 9 [12].

$$
\begin{aligned}
& \mathrm{CH}_{4}+2 \mathrm{O}_{2} \rightarrow \mathrm{CO}_{2}+2 \mathrm{H}_{2} \mathrm{O}+212 \frac{\mathrm{kCal}}{\mathrm{mol}} \\
& 212 \frac{\mathrm{kcal}}{\mathrm{mol}} * 40,98 \frac{\mathrm{mol}}{\mathrm{m}^{3}} * \frac{1 \mathrm{kWh}}{860 \mathrm{kcal}}=5,05 \frac{\mathrm{kWh}}{\mathrm{m}^{3}}
\end{aligned}
$$

\section{Results and discussions}

\subsection{Determination of the sample}

The sample size was $20 \mathrm{~kg}$ and the parameters established in the methodology section was used for the calculation. The size of the population used was determined from 13465.05 tons of garbage that stayed within the landfill during two years, from January 2015 to December 2016.

\subsection{Waste classification}

The weights of the different types of USW have been chosen from the $20 \mathrm{~kg}$ of garbage which stayed within the landfill during the study period each day. Based on the statistical data, that the variation of the weights for the types of USW between those days will depend on the activities that were carried out in the private homes of Salcedo. Regardless, two types of USW with the highest amounts were observed: organic waste and garden waste, and they are considered as biomass. In fact, it is advantageous to have them in high quantities, due to the fact that they together with paper and cardboard formed the raw materials for the biogas production.

The high deviation indicates that the data are much dispersed among them, which means that the values do not repeat frequently and move away from the average value, taking away the importance of the latter. By contrast, a low deviation represents that the values are repeated and that they do not have great variability with reference to the mean value [13].. So, the deviations of 
the different types of USW reveal that these weights depended directly on the daily activities of the local population of Salcedo. The comparison between the averages of the different types of USW showed that there were higher amounts of organic and garden waste that exceeded the averages of the others during the 36 days of sampling.

\subsection{Contribution of the USW for Biogas generation}

The biomass (i.e. cardboard, paper, organic garbage and garden) represented $63 \%$ of the total weights, wherein $450.9 \mathrm{~kg}$ of the total USW were sampled $(720 \mathrm{~kg})$ during the 36 days (from Monday to Friday). Figure 2 shows, that the inert materials, glass, and metal have the lowest contribution percentage $(1-5 \%)$ while the miscellaneous and plastics made a considerable contribution (both of 14\%). However, their influences were not as significant, since it is assumed that they were re-used in different aspects of the community / production process except for health miscellaneous (ready for final degradation).

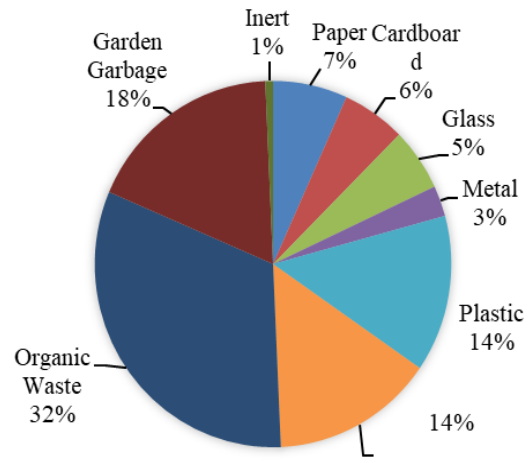

Fig. 2. Contribution of USW during the period 2016-2017

\subsection{Data Projection using NNB}

The designed NNB has an input layer and an output layer, together with two hidden layers of 10 and 6 neurons respectively; they obey the Backpropagation for Neural Networks training algorithm. As described in previous lines, their training consisted of feeding the network with a subset of variables listed in Table 3 which were obtained from the data that was taken between 2015 and 2016 as the fundamental basis of learning the network and its respective projection in estimating the same variables in Table 3 until 2030, as per the training of 58 periods and with a learning rate of $3.6152 \mathrm{E}-10$, as can be seen in Fig. 3.

Table 3 represents a projection of the values obtained as inputs for the generation of urban solid waste in the city of Salcedo which, among other things, included demographic, geographic, economic, industrial, social and consumer aspects.

From the application of the NNB, a data projection closer to reality was obtained, because it takes values of different types that affect the generation of waste by people living in the area of study. This type of model estimates the generation of USW based on patterns of income and consumption behavior of each household. This projection shows an annual increase in the generation of USW as shown in Table 4.
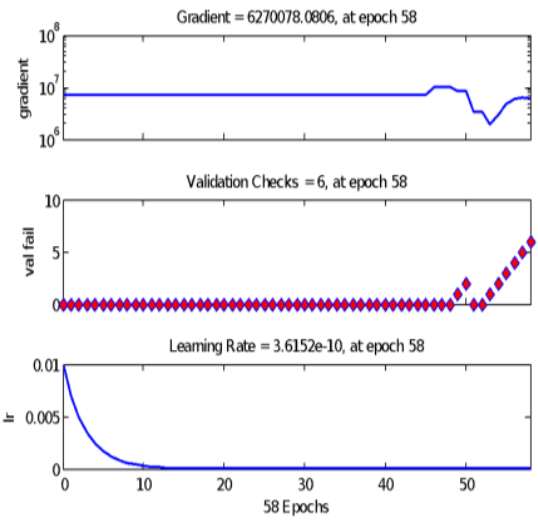

Fig. 3. NNB training

Table 3. Input values for the NNB

\begin{tabular}{|c|c|c|c|c|}
\hline $\begin{array}{c}\text { INPUT } \\
\mathbf{N}^{\circ}\end{array}$ & VARIABLE & UNITS & 2015 & 2016 \\
\hline 1 & $\begin{array}{l}\text { Gross Domestic } \\
\text { Product (GDP) }\end{array}$ & \$ million & $\begin{array}{l}1,00 \mathrm{E} \\
+05\end{array}$ & $\begin{array}{l}9,78 \mathrm{E} \\
+04\end{array}$ \\
\hline 2 & Urban population & Fraction & $\begin{array}{l}5,82 \mathrm{E} \\
+04 \\
\end{array}$ & $\begin{array}{l}5,82 \mathrm{E} \\
+04 \\
\end{array}$ \\
\hline 3 & $\begin{array}{l}\text { Population } \\
\text { Density }\end{array}$ & $\begin{array}{c}\text { person } / \mathrm{k} \\
\mathrm{m}^{2}\end{array}$ & $\begin{array}{l}1,08 \mathrm{E} \\
+03\end{array}$ & $\begin{array}{l}1,08 \mathrm{E} \\
+03\end{array}$ \\
\hline 4 & $\begin{array}{l}\text { Average } \\
\text { household size }\end{array}$ & $\begin{array}{c}\text { people } \\
\text { per } \\
\text { househol } \\
\text { d } \\
\end{array}$ & $\begin{array}{l}4,00 \mathrm{E} \\
+00\end{array}$ & $\begin{array}{l}4,00 \mathrm{E} \\
+00\end{array}$ \\
\hline 5 & $\begin{array}{l}\begin{array}{l}\text { Industry, added } \\
\text { value }\end{array} \\
\end{array}$ & Fraction & $\begin{array}{l}3,41 \mathrm{E} \\
+01\end{array}$ & $\begin{array}{l}3,41 \mathrm{E} \\
+01\end{array}$ \\
\hline 6 & $\begin{array}{l}\text { Tourism } \\
\text { expenses in the } \\
\text { country }\end{array}$ & $\begin{array}{l}\text { \$ per } \\
\text { person }\end{array}$ & $\begin{array}{l}6,16 \mathrm{E} \\
+01\end{array}$ & $\begin{array}{l}6,16 \mathrm{E} \\
+01\end{array}$ \\
\hline 7 & $\begin{array}{l}\text { Population by age } \\
\text { group of } 15-65\end{array}$ & Fraction & $\begin{array}{l}2,78 \mathrm{E} \\
+04\end{array}$ & $\begin{array}{l}2,78 \mathrm{E} \\
+04\end{array}$ \\
\hline 8 & $\begin{array}{l}\text { Household final } \\
\text { consumption } \\
\text { expenditure }\end{array}$ & $\$$ & $\begin{array}{l}3,92 \mathrm{E} \\
+06\end{array}$ & $\begin{array}{l}3,92 \mathrm{E} \\
+06\end{array}$ \\
\hline 9 & $\mathrm{CO}_{2}$ emissions & Fraction & $\begin{array}{l}1,11 \mathrm{E} \\
+05\end{array}$ & $\begin{array}{l}1,11 \mathrm{E} \\
+05\end{array}$ \\
\hline
\end{tabular}

Table 4. Annual data projection from 2017 to 2030.

\begin{tabular}{|c|c|}
\hline YEARS & TONS \\
\hline 2017 & $8,53 \mathrm{E}+03$ \\
\hline 2018 & $9,65 \mathrm{E}+03$ \\
\hline 2019 & $1,08 \mathrm{E}+04$ \\
\hline 2020 & $1,18 \mathrm{E}+04$ \\
\hline 2021 & $1,31 \mathrm{E}+04$ \\
\hline 2022 & $1,35 \mathrm{E}+04$ \\
\hline 2023 & $1,46 \mathrm{E}+04$ \\
\hline 2024 & $1,60 \mathrm{E}+04$ \\
\hline 2025 & $1,64 \mathrm{E}+04$ \\
\hline 2026 & $1,76 \mathrm{E}+04$ \\
\hline 2027 & $1,85 \mathrm{E}+04$ \\
\hline 2028 & $1,90 \mathrm{E}+04$ \\
\hline 2029 & $2,05 \mathrm{E}+04$ \\
\hline 2030 & $2,22 \mathrm{E}+04$ \\
\hline
\end{tabular}




\subsection{Estimation of the biogas energy potential}

In order to estimate the biogas energy potential, the percentage contribution of biomass was used. The application of the Mexican and Ecuadorian models for the determination of the volume of biogas generation were applied with biomass weights projected by the NNB for the period of 16 years (2015-2030). As shown in Fig. 4 , the defined percentage contribution influenced directly the production of biogas volume. Based on the data obtained, the highest amounts of waste was coming from the organic waste, which represented $32 \%$ of the total weight-based contribution of the waste where the other types of biomass presented the values of biogas volume according to their respective percentages.

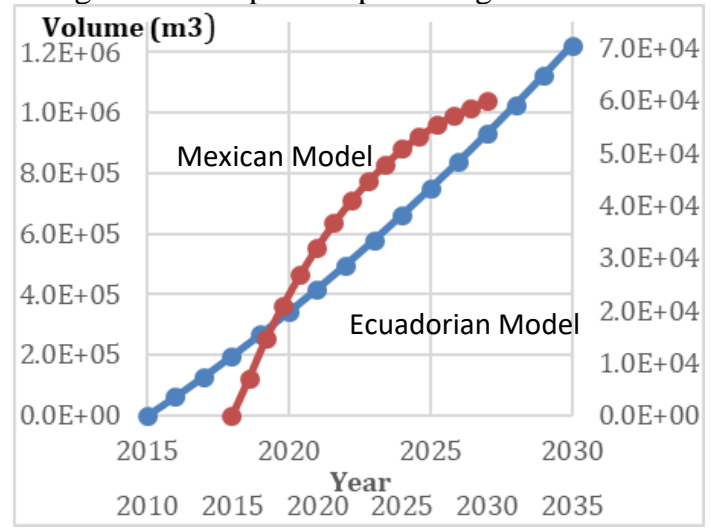

Fig. 4. Volume of biogas production, Mexican Model an Ecuadorian Model

Despite the existing differences between the two models that were used, both had calculated that the percentage of methane produced from biogas added up to $50 \%$, which had influenced the energy value $(5.05 \mathrm{~kW} / \mathrm{h})$ where the production volume of biogas was multiplied in order to transform the volume (m3) into energy values $(\mathrm{kWh})$. In the Mexican model, the annual average of the biogas energy potential was $3.76 \times 104 \mathrm{kWh}$, while in Ecuadorian model an annual average of $7.07 \times 105 \mathrm{kWh}$ was obtained. In both cases, the values obtained were significant as it had determined the possibilities of using the biogas acquired from the biomass in the sanitary landfill as alternative energy sources, as shown in Fig. 5.

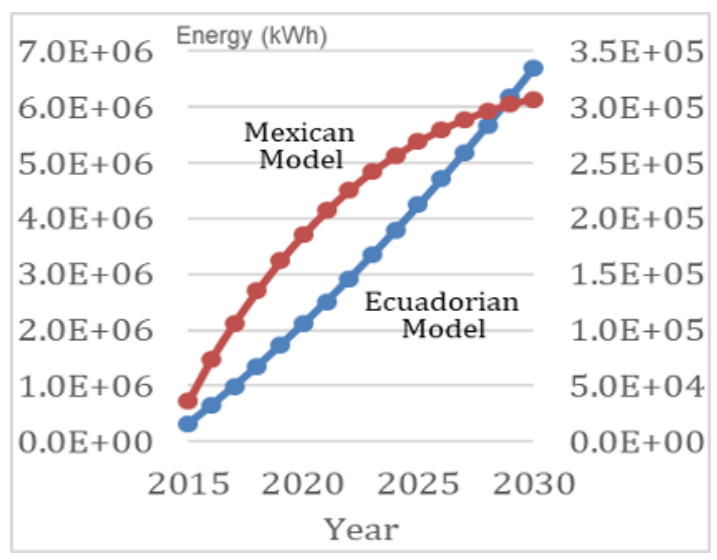

Fig. 5. Energy produced from the Biogas, Ecuadorian Model and Mexican Model.

\section{Summary}

The classification and quantification of urban solid waste generated in the city of Salcedo, Ecuador have shown that the amount of waste is directly proportional to the number of inhabitants, commercial and their daily activities. The determination of the contribution for each type of solid waste has shown that there was around $63 \%$ of biomass in the said city where the most significant contributors being organic waste and garden waste at the percentage rates of $32 \%$ and $18 \%$, respectively. In terms of the other types of waste which had accounted for $47 \%$, plastics and miscellaneous were ranked the highest at $14 \%$ among all other waste compared. The energy potential of the biogas obtained from the biomass was evaluated by comparing the Mexican and Ecuadorian biogas models where the waste weights were projected from 2015 to 2030. The Ecuadorian model presented the highest average volume of annual biogas generation (1.40 x $105 \mathrm{~m} 3$ ) and consequently a high annual energy potential $(7.07 \times 105 \mathrm{kWh})$. Finally, the application of the neural network model with back propagation allows has made possible a data projection which is closer to reality. In the application of neural networks with back propagation, the training algorithm was presented with the objective to minimize the number of errors on all the training sets where each iteration of training is called time and updated the weights of both the input and output layers, as well as the weights of the hidden layers. Last but not least, it is also worth mentioning that this approach in the future could allow the development of a Machine Learning in this area to provide a better estimation result for the Energy Potential of Biogas that is closer to the reality.

\section{References}

1. X. Wan, Y. Wang, D. Zhao, and Y. Huang, "A comparison of two types of neural network for weld quality prediction in small scale resistance spot welding," Mechanical Systems and Signal Processing, vol. 93, p. 634, (2017).

2. M. Jalili Ghazi Zade and R. Noori, "Prediction of Municipal Solid Waste Generation by Use of Artificial Neural Network: A Case Study of Mashhad," International Journal of Environmental Research, vol. 2, pp. 13-22, (2008).

3. E. Cérda, "Energy obtained from biomass," ICE economic notebooks, vol. 83, pp. 117-140, (2015).

4. C. Ochoa. (2008). Probabilistic sampling: simple random sampling. Available: https://www.netquest.com/blog/es/blog/es/muestreoprobabilistico-muestreo-aleatorio-simple

5. M. E. Edjabou, M. B. Jensen, R. Götze, K. Pivnenko, C. Petersen, C. Scheutz, et al., "Municipal solid waste composition: Sampling methodology, statistical analyses, and case study evaluation," ELSEVIER, 2014.

6. General Directorate of Standards, "NMX-AA-22-1985: Environmental protection - Soil pollution-Municipal 
Solid Waste - Selection and Quantification of byproducts," vol. 22, ed. Mexico, (1992).

7. M. A. Valencia Reyes, "Backpropagation Algorithm for Neural Networks: concepts and applications.," Computer Research Center, National Polytechnic Institute (2007).

8. S. Ojeda-Benítez, G. Lozano-Olvera, R. AdalbertoMorelos, and C. Armijo de Vega, "Mathematical modeling to predict residential solid waste generation," Waste Management, vol. 8, p. 7, 2008.

9. V. M. Adamović, D. Z. Antanasijević, M. Đ.Ristić, A. A. Perić-Grujić, and V. V. Pocajt, "Prediction of municipal solid waste generation using artificial neural network approach enhanced by structural break analysis," Environ Sci Pollut Research, vol. 24, p. 13, (2017).

10. P. Cardenas, "Estimation of biogas and leachate generated in final disposal sites of solid urban waste in the State of Mexico," Professional interdisciplinary biotechnology unit, National Polytechnic Institute, Mexico, (2014).

11. INAMHI, "Annual climatological bulletin 2015," INAMHI, Quito (2016).

12. M. Diaz Piñón. How to evaluate biogas digesters. Available: http://www.cubasolar.cu/biblioteca/Energia/Energia5 0/HTML/Articulo07.htm

13. E. Mode, Elements of probability and statistics. USA: Reverte, (1990). 